Abbreviated Key Title: Sch J Med Case Rep

ISSN 2347-9507 (Print) | ISSN 2347-6559 (Online)

Journal homepage: http://saspjournals.com/sjmcr

\title{
Spontaneous Pneumomediastinum as an Anxiety Hysteria Consequence
}

Nuno Zarcos Palma*, Mariana da Cruz, Catarina Couto, Vítor Fagundes, Alice Castro, Mari Mesquita

Internal Medicine Department of Centro Hospitalar Tâmega e Sousa

DOI: $10.36347 /$ sjmcr.2020.v08i01.009

| Received: 05.01.2020 | Accepted: 12.01.2020 | Published: 16.01.2020

*Corresponding author: Nuno Zarcos Palma

Abstract

Case Report

A 21-year-old girl had a sudden onset of thoracic pain and shortness of breath after anxiety hysteria. After two days the patient came to the emergency department for swollen neck. Physical examination revealed crackles in the subcutaneous cellular tissue. Spontaneous pneumomediastinum was diagnosed, and the patient was admitted for close monitoring. On follow up she had complete resolution of the pneumomediastinum.

Keywords: Spontaneous pneumomediastinum, subcutaneous emphysema, swollen neck.

Copyright @ 2020: This is an open-access article distributed under the terms of the Creative Commons Attribution license which permits unrestricted use, distribution, and reproduction in any medium for non-commercial use (NonCommercial, or CC-BY-NC) provided the original author and source are credited.

\section{INTRODUCTION}

Spontaneous pneumomediastinum is defined as the presence of air in the mediastinum in the absence of trauma [1]. The cause of spontaneous pneumomediastinum includes asthma, respiratory tract infections, vomiting or coughing, intensive effort or Valsalva maneuver [2].

The most common symptoms directly related to the spontaneous pneumomediastinum are subcutaneous emphysema, dyspnea and pleuritic chest pain. On physical examination patients can present subcutaneous emphysema or a Hamman's crunch that is a characteristic crunching sound synchronous with systole. The diagnostic is confirmed by plain films of the chest [3].

\section{Case Report}

A 21-year-old girl with previous diagnosis of Obsessive-Compulsive Disorder (OCD) medicated with fluoxetine, had a sudden onset of thoracic pain and shortness of breath after anxiety hysteria, during which she was yelling for several minutes. Two days after the onset of symptoms, the patient came to the emergency department for swollen neck and dyspnea. Physical examination revealed crackles in the subcutaneous cellular tissue. Complete blood count and serum biochemistry profiles were unremarkable. The chest radiograph(Image-1) showed pneumomediastinum and subcutaneous emphysema in the supra clavicular and cervical regions. These findings suggested the presence of pneumomediastinum and a chest CT scan (Image-2) was performed confirming extensive subcutaneous emphysema of the neck, pneumomediastinum and excluding pneumothorax, fracture of the costal arches or bronchopleural fistulas. There was no evidence of mediastinitis or esophageal rupture.

Spontaneous pneumomediastinum was diagnosed, and the patient was admitted to Intensive Care Unit for close monitoring. Analgesic treatment was administrated, and discharged was possible 5 days after admission.

Follow-up chest CT scan was performed one week later which demonstrated complete resolution of the pneumomediastinum. On follow-up consultation she was asymptomatic with no recurrences.

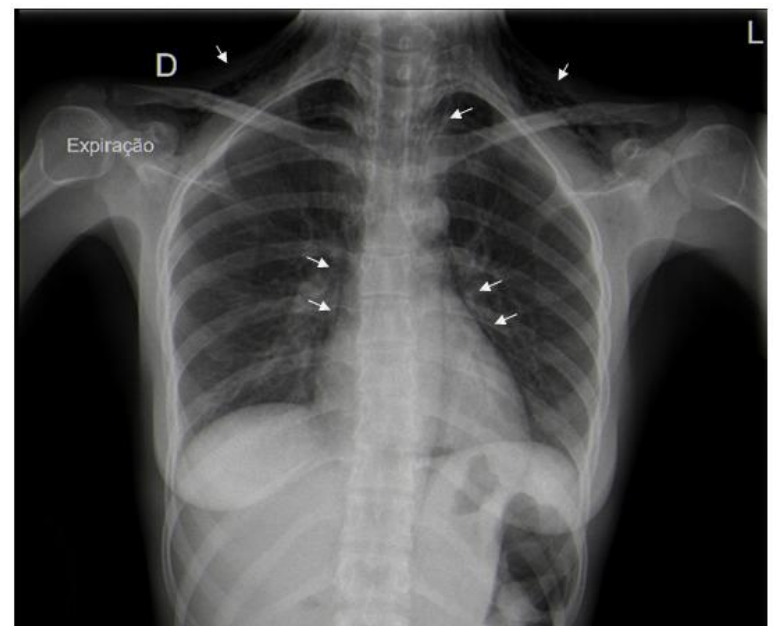

Image-1: The posteroanterior plain chest radiograph showing 
signs of pneumomediastinum and subcutaneous emphysema in soft tissues (arrows).

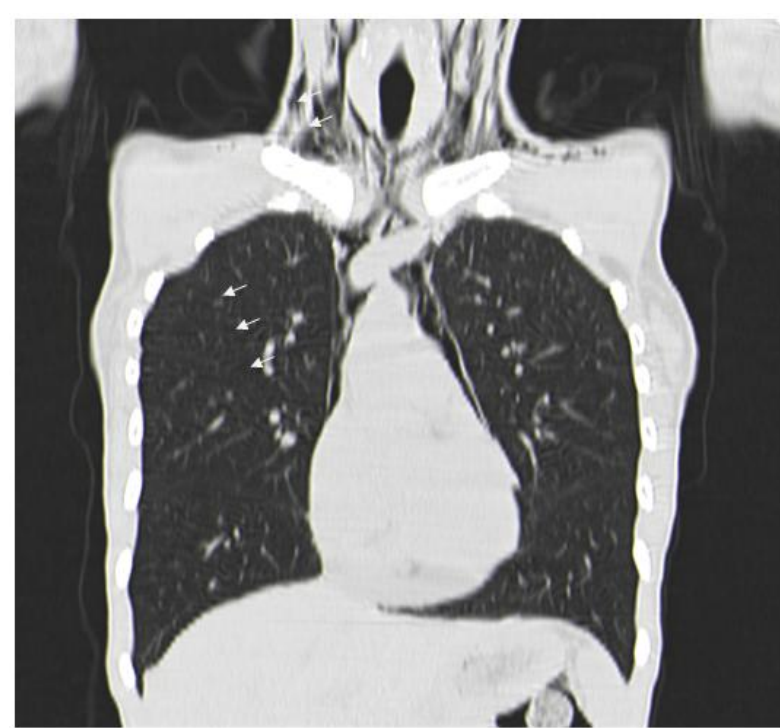

Image-2: The chest computed tomography scan showing the presence of interstitial air surrounding the structures within the mediast and neck (arrows)

\section{DisCUSSION}

Spontaneous

pneumomediastinum

is frequently secondary to intensive effort or Valsalva maneuver. This patient had anxiety hysteria that result in an extensive pneumomediastinum, only detected after few days because of subcutaneous emphysema.

Simple spontaneous pneumomediastinum has a benign course and does not require hospitalization [4]. In this case, the need for hospitalization was imposed by the progressive worsening of dyspnea and emphysema, day after day. Due to the potential for aggravation, the patient was hospitalized and maintained continuous monitoring until clinical stability was assured.
Serial radiographs, likewise, did not change the medical management of spontaneous pneumomediastinum [4]. Although, computed tomography, serial radiographs and analyzes was performed to exclude complications such as perforation or mediastinitis, once patient came only after some days and symptoms in worsening.

\section{CONCLUSION}

This case caveats the importance of value the patients' complaints to determine the diagnose. The goals of evaluation are assessing the etiology, to prevent future events like Valsalva maneuvers in this case.

Not all patients need to be admitted to the Hospital. The stable patients with simple spontaneous pneumomediastinum have a benign course with conservative therapy.

Looking back, this patient did not benefit from serial imaging examinations, as described in the literature.

\section{REFERENCES}

1. Mason, R. Pneumomediastinum and mediastinitis. In: Murray and Nadel's Textbook of Respiratory Medicine, 4th ed, Elsevier Health Sciences, 2005. Chapter 72.

2. McMahon DJ. Spontaneous pneumomediastinum. Am J Surg. 1976; 131:550.

3. Yellin A, Gapany-Gapanavicius M, Lieberman Y. Spontaneous pneumomediastinum: is it a rare cause of chest pain? Thorax. 1983; 38:383.

4. Panacek EA, Singer AJ, Sherman BW, Prescott A, Rutherford WF. Spontaneous pneumomediastinum: clinical and natural history. Ann. Emerg. Med. 1992;21:1222-1227. 